\title{
Pela pele: o papel da cultura visual e da ceroplastia na constituição da dermatologia como especialidade médica na Europa
}

\author{
Through the Skin: The Role of Visual Culture \\ and Ceroplastics in the constitution of \\ Dermatology as a Medical Specialty in Europe
}

Jorge Carreta*

\section{RESUMO}

$\mathrm{O}$ artigo analisa o surgimento da dermatologia como especialidade médica, situando-a no contexto das transformações mais amplas trazidas pelos estudos anatômicos, pelas mudanças na classificação das doenças e pelas transformações na cultura visual desde o século XVI. Em um segundo momento, procura estabelecer a relação entre aquelas mudanças, que favoreceram a constituição das especialidades médicas, e a moulage, a modelagem das doenças da pele em cera, atividade de grande importância para a consolidação da dermatologia como especialidade médica. Palavras-chave: história da medicina; dermatologia; especialidades médicas; ceroplastia; moulage dermatológica.

\begin{abstract}
This paper analyzes the emergence of dermatology as a medical specialty, situating it in the context of the broader transformations brought by anatomical studies, changes in the classification of diseases and transformations in the visual culture since the 16th century. It also seeks to establish the connections between those changes, which favored the constitution of medical specialties, as well as moulage, a technique of modeling skin diseases in wax, which was of great importance for the dermatology's consolidation as a medical specialty.

Keywords: medicine history; dermatology; medical specialties; ceroplastics; dermatological moulage.
\end{abstract}

* Faculdades de Campinas (Facamp), Campinas, SP, Brasil. jorgecarreta@yahoo.com.br <https://orcid. org/0000-0002-8882-2660> 
Em A pele que habito (2011), filme do cineasta espanhol Pedro Almodóvar, o cirurgião plástico Robert Ledgard, personagem vivido por Antonio Banderas, busca um substituto para a pele humana que seja resistente ao calor, ao frio e a picadas de inseto. Usando genes de suínos combinados aos de humanos, o médico chega a uma pele que é quase uma casca, uma verdadeira fronteira entre o indivíduo e o mundo que o rodeia. Tratava-se literalmente de "fechar o corpo" daquele que recebesse a nova e melhorada pele. Certas doenças cutâneas desapareceriam, assim como ficaria mais difícil a ação daqueles patógenos que se introduzem pela pele. Os mosquitos transmissores de malária ou da dengue não conseguiriam perfurar a nova "armadura".

O desenrolar da história surpreende o espectador. Apesar de seus objetivos aparentemente nobres, o dr. Ledgard empenha-se em levar a cabo uma vingança contra um jovem que teria molestado sexualmente sua filha. A nova pele não conferia apenas proteção, mas a possibilidade de mudar a identidade de seu receptor de forma radical. O suposto agressor é transformado em uma bela mulher, pela qual o cirurgião se apaixona.

O filme de Almodóvar é um ponto de partida possível para pensarmos como a pele é um componente central da identidade individual contemporaneamente. Siena e Reinarz (2013) mostram como a pele, concebida antes da Modernidade como algo poroso, em contato direto com o mundo, transforma-se em uma grossa barreira que separa o "eu" (self) do meio exterior. No século XIX já podemos encontrar a noção de que o corpo deve ser fechado, "impenetrado", isto é, um corpo saudável. ${ }^{1}$

O surgimento das preocupações com as doenças da pele insere-se nesse contexto de transformação da identidade individual. Com a noção de identidade fortemente ligada à saúde da extensa "capa" que recobre inteiramente o corpo humano, os estigmas provocados pelas doenças cutâneas tornaram-se terríveis. O combate à peste, à lepra e à sífilis, por exemplo, envidava esforços dos médicos e recursos dos governos. Se a identidade individual se tornou chave a partir do Iluminismo, as doenças que provocavam desfiguração afetavam-na diretamente. As sociedades liberais-democráticas, emergentes no século XVIII, são aquelas dos rostos à mostra, sem máscaras, e as doenças que escondiam a face traziam um perigo social evidente. ${ }^{2}$

Como assinalam Siena e Reinarz (2013, p. 3), a pele, além de fronteira, pode ser lida como um texto ou um mapa. Os atlas dermatológicos, cuja aparição remonta ao século XVIII, reforçam essa visão. Os termos dos geógrafos são apropriados pelos médicos e surgem os "panoramas da pele" (skinscapes) 
ou os "panoramas corporais" (corporal landscapes). As doenças de pele, por meio dessa terminologia, ganham "visibilidade e significado". Elas são, por assim dizer, o relevo na textura plana da pele. Cada uma constrói uma paisagem nesse terreno.

A pele, é preciso dizer, não é lisa ou suave, como tanto desejamos. É marcada por imperfeições de todo tipo: rugas, buracos, aspereza, oleosidade etc. A indústria cosmética surge impulsionada pelo desejo de uma pele uniforme, macia e sem odores desagradáveis. A superfície corporal é um “outdoor” (advertising billboard) no dizer de Di Folco (2004, p. 8 apud Siena; Reinarz, 2013, p. 3).

Ainda no terreno da geografia, a pele é vista como uma fronteira que separa o interior do indivíduo do mundo exterior. Ela não faz apenas a contenção dos fluidos internos, como o sangue, e elimina substâncias indesejáveis por meio do suor, mas impede a entrada de corpos estranhos e potencialmente nocivos. Trata-se de uma estrutura de transição entre o interno e o externo, de proteção e demarcação, tal como as modernas fronteiras entre os países. Como observa Wilson (2013, p. 209), o estudo das doenças de pele é o estudo do espaço e do lugar. Certas doenças estão ligadas a espaços específicos (países, cidades, regiões), assim como relacionadas a lugares particulares do corpo. O corpo é, pois, um mapa.

O interior do corpo é escuro e as estruturas internas estão escondidas, imersas em líquidos e embaraçadas entre músculos, ossos, tendões e gordura. A pele, ao contrário, apresenta-se inteira à visão do médico. Graças a essa característica, a produção de imagens sobre as doenças de pele foi prolífica. Por serem externas, as afecções e seus desenvolvimentos podiam ser acompanhados em detalhes.

Os atlas dermatológicos (o uso do termo "atlas" reforça a metáfora geográfica proposta por Wilson) tinham as imagens como elementos centrais. Os textos eram secundários. As imagens dominavam a visão e a imaginação do leitor. A era dos atlas dermatológicos, dizem Siena e Reinarz (2013, p. 4), "conduziu o material visual para o palco central nas representações médicas da pele".

A pele também esteve situada no processo de dessacralização do corpo, como o chamou Le Breton (2011, p. 47). Na modernidade, o homem é separado de seu corpo, o que era negado pela cultura popular da Idade Média e do Renascimento. No dizer de Bakhtin, havia o "grande corpo da espécie". A carne não separava o homem do mundo, não era um limite, mas comunicava-se, de poros abertos, com o exterior. Os estudos anatômicos marcam um 
momento de transição no qual o corpo passa a ser observado como algo apartado do cosmo, como universo independente, passível de estudo.

A separação entre tal corpo dessacralizado e o mundo é feita sobretudo pela pele. Não é por acaso que diversos atlas anatômicos mostram modelos humanos segurando a própria pele, oferecendo à visão as estruturas internas. Esse invólucro opaco que recobre todo o corpo é o primeiro obstáculo a ser removido. Os atlas anatômicos, a partir do século XVI, trazem em seus frontispícios ou em suas páginas imagens de homens esfolados, chocantes para a época. ${ }^{3}$ É bastante conhecida a imagem de São Bartolomeu no afresco pintado por Michelangelo nas paredes da Capela Sistina, no Vaticano. O santo, cujo martírio foi o esfolamento, segura sua própria pele em uma das mãos. $\mathrm{Na}$ outra, um alfanje, uma adaga curta, o instrumento de seu suplício. Sabe-se que Michelangelo e Leonardo da Vinci, artistas destacados do Renascimento, foram hábeis dissecadores, prática que lhes permitiu o conhecimento de anatomia para o uso em suas obras.

Le Breton (2011, p. 57), referindo-se ao avanço desse processo de "dessacralização" do corpo humano, compara a dissecação anatomista às relíquias dos santos. Os pedaços dos corpos de pessoas canonizadas não eram adorados individualmente, mas representavam a metonímia da glória divina. As relíquias encarnam toda a Igreja e são a parte tangível de toda a comunidade divina. São figuras de intercessão, lembrança e expressão da submissão a Deus. Na dissecação anatômica, as partes do corpo são vistas individualmente, separadas do todo, apenas constituintes das vísceras.

As primeiras dissecações anatômicas expressam o desprezo pelas profissões que faziam "correr sangue" (barbeiro, açougueiro, cirurgião, carrasco), como lembra Jacques Le Goff (2013, p. 118). Daí os primeiros anatomistas se valerem dos cirurgiões para não tocarem o corpo. Ao médico cabia apenas confirmar os livros-texto, apontando as estruturas internas do corpo que iam sendo reveladas pelo trabalho do cirurgião. O demonstrator, um cirurgião, fazia a abertura do corpo. O texto era lido pelo professor, e o ostensor indicava com uma varinha a parte do corpo descrita. Por vezes, ele repetia literalmente as palavras do mestre, usualmente colocado em um patamar superior, sentado em um tipo de cátedra.

De acordo com Lebrun (1985, p. 287), na França do final do século XIII institucionalizou-se a dissociação da técnica de curar em dois domínios: a medicina e a cirurgia. A primeira estava ligada ao conhecimento dos livros e à universidade, enquanto a segunda estava relacionada à execução de práticas receitadas pelos médicos, tais como as sangrias, incisão em abscessos, 
curativos ou redução de fraturas. A medicina era identificada com as "artes liberais" e a cirurgia com as "artes mecânicas", representadas pelos artesãos, colocados profissionalmente, no meio urbano, na mesma comunidade dos barbeiros. Será somente no século XVIII, após a Revolução de 1789, que a cirurgia agregar-se-á ao ensino médico como especialidade. ${ }^{4}$

Outro aspecto interessante enfatizado por Le Breton é a transformação que ocorre, a partir do século XV, na arte do retrato. Há uma gradual transição do sagrado para o profano, segundo ele. $\mathrm{O}$ cristianismo desencorajava a feitura de retratos individuais, salvo aqueles dos grandes homens do Estado ou da Igreja, sempre acompanhados de pessoas divinas. Representavam-se preferencialmente grandes eventos bíblicos ou da Antiguidade. Isso mudou com a ascensão da burguesia, que trouxe consigo a ideologia do individualismo. Os ricos comerciantes passaram a demandar o trabalho dos grandes mestres para retratar a si e sua família. As referências religiosas nesses quadros desapareceram ou foram relegadas ao segundo plano (Le Breton, 2011, p. 65).

O indivíduo tornou-se a cogitação principal da expressão artística, destacando-se a representação dos rostos e feições. Ele deixou de ser um corpo indistinto, pertencente a uma comunidade universal, para se tornar alguém único, exclusivo e proprietário de si. A face é única: a marca e a cifra de cada pessoa. A individuação pelo corpo se concentrou na individuação pelo rosto (Le Breton, 2011, p. 66). Cabe aqui um paralelo entre essa transformação e a penetração da personalidade no domínio público, como descreve Sennett (1988).

Para Sennett, a personalidade emerge no século XIX desvinculada da concepção iluminista do "caráter natural", que representava o elo entre todos os homens. As experiências de vida não moldam o caráter, mas o revelam. Nos Oitocentos, admite-se o caráter individual, que varia de uma pessoa para outra. As aparências refletem a vida interior. Assim, diferentes aparências nos falam de diferentes caracteres, que são, por sua vez, criados pelas experiências de vida e pelas próprias ações do indivíduo. Há uma imanência entre a personalidade e a aparência: o que aparece é o que vai por dentro da pessoa. As roupas, por exemplo, não escondem os sentimentos e a vida interior, mas os revelam, são pistas da personalidade (Sennett, 1988, p. 194).

Cremos ser possível se valer dessa interpretação (o exterior revelando o interior) para compreender como eram vistas as doenças cutâneas. Pode-se imaginar o estigma que recaía sobre o indivíduo com a pele deformada. A maior parte do corpo podia ser escondida debaixo das roupas, mas a face estava sempre à vista. Siena e Reinarz $(2013$, p. 1) ilustram o horror que cercava as doenças de pele ao trazer o relato do caso de Richard Challenger, 
assassinado em 1739, na cidade de Londres, por sua senhoria Elizabeth Bradford. Ao cobrar-lhe o aluguel atrasado, Bradford empurrou Challenger escada abaixo. O inquilino bateu a cabeça e expirou. A senhoria foi a julgamento, mas o alvo efetivo das atenções na corte foi a pele de Challenger. Recoberto de cascas e feridas, causava aversão a todos que o conheceram. $\mathrm{O}$ legista sugeriu que a sua morte teria se dado não pela queda, mas por uma condição prévia, provavelmente uma doença venérea que enfraquecera Challenger e se manifestava por meio de múltiplas feridas externas. Essa aparência repulsiva da vítima parece ter tido influência decisiva, pois após o julgamento Elizabeth Bradford foi libertada.

Esse episódio revela o desprezo instalado pelas doenças que afetavam a pele, naquele momento já concebida como a fronteira entre o homem e o mundo, além de espelho de seu caráter e o reflexo da sua conduta. A dermatologia vai se constituir como especialidade no século XIX com a preocupação de compreender e tratar as afecções da pele, sobretudo aquelas deformantes.

A seguir, indicaremos como essas mudanças de concepção em relação ao corpo e ao indivíduo, aliadas à emergência de uma nova cultura visual na medicina, abriram caminho para a constituição de um campo médico que se dedicava exclusivamente ao estudo das doenças da pele. No esforço para estabelecer a especialidade médica que mais tarde seria conhecida como dermatologia, os médicos e cientistas naturais empenharam-se na descrição e classificação das afecções cutâneas.

No século XIX, a modelagem patológica (ou moulage) agrega-se ao processo de constituição da dermatologia como especialidade, tornando ainda mais visíveis as doenças de pele. Propomos indicar que a moulage teve papel importante no processo de especialização da dermatologia, elegendo determinadas afecções que deviam ser estudadas e combatidas.

\section{A DeRMatologia E A ClAsSifiCAÇÃo DAS DOENÇAS}

Os termos "dermologia" e "dermatologia" teriam surgido em meados do século XVIII para se referir às membranas corporais, inclusive a pele, nos estudos de médicos anatomistas e patologistas (Benchimol, 2004, p. 45). Contudo, a pele humana não era vista como um órgão e suas afecções apenas refletiriam a doença de órgãos internos. Aos poucos, essa concepção mudou e ela passou a ser vista como local de condições patológicas específicas, que poderiam ser descritas e tratadas. 
Foi somente no início do século XIX que a pele passou a ser tratada como um órgão importante e distinto. Na Alemanha, entre 1820 e 1850, em sintonia com as mudanças no conhecimento da anatomia e da fisiologia, os estudos sobre a pele ganharam relevância. A partir de estudos microscópicos, anatomistas e fisiologistas alemães produziram desenhos representando a estrutura anatômica da pele saudável e da pele enferma (Hennepe, 2009, p. 5152). Contudo, por volta de 1860, como indicam Haviland e Parish (1970), a dermatologia ainda fazia parte das disciplinas médicas iniciantes.

$\mathrm{O}$ aspecto evidente das doenças de pele e o surgimento da anatomia patológica, que concentrou a atenção nas lesões, igualmente contribuíram para o desenvolvimento da dermatologia como especialidade. Na fisiologia, consolidava-se a noção do estudo experimental dos órgãos, tidos como "princípios básicos”. A pele passa a ser vista como um órgão independente, não apenas uma simples camada protetora do corpo, tal como na visão galênica. Suas afecções passaram a demandar atenção especial.

Na universidade alemã, Jan Evangelista Purkinje (1787-1869) conduziu experimentos tendo por princípio a consideração de que a pele era um sistema de conformação orgânica. As experiências buscavam elucidar as funções táteis e excretoras da pele. Tais estudos marcam, segundo Hennepe, um ponto de inflexão na concepção sobre a pele, que deixará de ser vista no século XIX como um sistema poroso e aberto ao mundo e se transformará em barreira espessa de defesa e de delimitação em relação ao meio externo (Hennepe, 2009, p. 56-57).

Os médicos e fisiologistas que estudavam as doenças da pele definiram seu âmbito de atuação ao se concentrarem na descrição minuciosa das lesões, que se apresentavam "puras", sem a necessidade de intervenção cirúrgica para serem reveladas. Os pacientes eram observados ainda em vida, pois as lesões internas só podiam ser vistas durante as autópsias. Também era possível acompanhar o curso da doença e estabelecer seus estágios e sintomas específicos.

As manifestações patológicas da pele permitiram a construção de uma "gramática visual" para classificar as doenças. Isso trouxe alguns problemas, já que era necessária a descrição acurada para evitar enganos nos diagnósticos e, consequentemente, na prescrição do tratamento. Note-se que tais manifestações não eram mais tidas como simples sintomas de doenças internas, ao contrário do que pensava o importante fisiologista e anatomista francês Xavier Bichat (1771-1802), que considerava as doenças da pele como manifestações de processos orgânicos que se davam dentro do corpo (Benchimol, 
2004, p. 46). As sutis diferenças entre as lesões cutâneas tinham de ser rigorosamente estabelecidas para a fixação de uma nosografia da pele.

Segundo Hennepe (2007), não havia o costume de representar as doenças de pele nos livros médicos até fins do século XVIII. É no século seguinte que os médicos preocupados com essas doenças começam a ordená-las através de imagens. Fend (2013) também mostra como as imagens ganharam importância a partir do século XIX, pois podiam representar as lesões de pele de forma mais acurada. As peças anatômicas em conserva nos museus tendiam a descolorir e enrugar. Relacionado às teorias classificatórias das doenças, emergiu um "complexo cenário de regras tácitas e convenções" buscando formar uma linguagem visual para a representação das doenças de pele (Hennepe, 2007, p. 22).

O médico inglês Robert Willan (1757-1812) é tido por vários autores como o fundador da dermatologia como disciplina médica. ${ }^{5}$ Ele publicou em 1798 o livro Description and Treatment of Cutaneous Diseases, que trazia desenhos coloridos de doenças de pele. ${ }^{6}$ Sua terminologia de classificação simbolizou o momento inicial da dermatologia profissional, e seus desenhos (gravuras e aquarelas) forneceram os "ingredientes pictóricos para a linguagem visual das doenças de pele no século XIX” (Hennepe, 2007, p. 23).

Willan, influenciado pelo trabalho taxonômico de Carl Lineu (17071778), valia-se de critérios morfológicos para representar as doenças. Buscando escapar à confusão classificatória, que reduzia as enfermidades cutâneas a dois ou três tipos, o médico inglês propôs oito ordens de classificação: 1) pápulas; 2) escamações; 3) erupções; 4) bolhas; 5) pústulas; 6) vesículas; 7) nódulos; 8) manchas. Todas as doenças poderiam ser enquadradas em uma dessas categorias. A intenção era estabelecer uma linguagem comum e facilitar o diagnóstico e tratamento. Seus desenhos vinham auxiliar a compreensão dessa classificação. Willan dizia que a aparência de algumas doenças "não podia ser claramente comunicada em palavras". Contudo, ele também estava ciente da limitação da representação pictórica das lesões:

Tais representações não podem expressar suficientemente os vários graus de opacidade e transparência das pústulas; nem a quantidade de material supurada de ulcerações superficiais; nem podem acompanhar a cada minuto as circunstâncias da evolução da doença, sendo necessariamente feitas em um período fixo dela. (Willan, 1808, p. x-xi apud Hennepe, 2007, p. 29, trad. nossa) 
Entretanto, "número, tamanho, forma e cor" eram aspectos que podiam transcender as palavras e permitir um entendimento mais apurado das doenças de pele do que as descrições textuais. Para Hennepe (2007, p. 29), estabeleceu-se uma forte ligação entre classificação e visualização.

Na França, Jean-Louis Alibert (1768-1837) desenvolveu outra maneira de classificar as doenças de pele. ${ }^{7} \mathrm{~A}$ inspiração era a mesma do método "willanista": a história natural dos Setecentos. Alibert falava em uma classificação "natural” das doenças, refletindo um debate presente na ciência botânica francesa entre "artificialistas" e "naturalistas". Os primeiros agrupavam as plantas de acordo com poucas características; os segundos observavam várias características, tudo o que a natureza oferecia aos olhos. ${ }^{8}$ Esse método seria mais próximo da natureza, daí o nome que recebeu (Tilles; Wallach, 2002, p. 68).

A partir de 1829, o médico francês introduziu uma nova abordagem na qual as doenças, chamadas de dermatoses, eram divididas em doze famílias: dermatoses eczematosas, dermatoses exantematosas, dermatoses heteromorfas, dermatoses discromatosas, dermatoses hematosas, dermatoses tinhosas, dermatoses cancerosas, dermatoses leprosas, dermatoses escrofulosas, dermatoses de feridas, dermatoses de sarnas e dermatoses sifilíticas (aqui incluídas as micoses). Alibert representou essas famílias no desenho de uma árvore com 12 galhos para indicar que entre elas havia pontos de semelhança, diferentemente dos willanistas, que viam as doenças como entidades individuais (Tilles; Wallach, 2002, p. 69).

Não obstante os esforços de Alibert, a nosografia da pele de Willan e Bateman predominou desde 1816. Os "willanistas franceses" ocuparam os espaços de pesquisa e ensino, até mesmo aqueles da clínica de Alibert no Hôpital Saint-Louis. O destaque dado pela classificação de Willan à morfologia das lesões de pele vai ao encontro dos desenvolvimentos da anatomia patológica no ambiente hospitalar francês. Há uma mudança da atenção aos sintomas para as lesões como forma de diagnóstico. Os esforços do willanistas franceses serão decisivos para a difusão da classificação Willan-Bateman por toda a Europa. Eles adotam as técnicas de representação pictórica desenvolvidas por Willan' (Hennepe, 2007, p. 38).

É visível a importância crescente das representações gráficas para auxiliar a compreensão e identificação das doenças de pele. Pierre Rayer publicou em 1826 um tratado sobre as afecções cutâneas acompanhado de um atlas ricamente ilustrado (Traité théorique et pratique des maladies de la peau, fondé sur de les nouvelles recherches d'anatomie et de physiologie pathologiques). As gravuras teriam papel crucial no treinamento médico. $\mathrm{O}$ autor pretendia usar 
sua obra para comunicar suas observações e descobertas para alunos de medicina (Hennepe, 2007, p. 40).

Outro ponto interessante é a escolha de Rayer de representar apenas as lesões elementares em uma região do corpo, sem a necessidade de mostrar outros locais afetados. Essa visão "compartimentalizada" também estava presente na Inglaterra, como atesta a obra de Anthony Todd Thomson (17781849), Atlas of Delineations of Cutaneous Eruptions, publicada em 1829. De acordo com Hennepe

A continuação da maneira localista, fragmentada e compartimental de representar doenças de pele de Rayer e Thomson demonstra o início de uma linguagem visual da pele enferma. [...] As duas maneiras de representação são visualmente comparáveis e funcionavam em ambientes educacionais. Enquanto a descrição compartimental de Rayer enfatizava as lesões elementares como uma base analítica para as doenças de pele, os fragmentos coloridos da pele doente de Thomson foram feitos como uma prática ajuda visual aos estudantes. (Hennepe, 2007, p. 42 , trad. nossa)

Apesar da predominância da representação pictórica de Willan e Bateman, a observação baseada na tradição clínica defendida por Alibert não despareceu. $\mathrm{O}$ médico francês costumava representar não apenas a parte do corpo afetada pela doença, mas o paciente inteiro, incluindo em seus desenhos detalhes pessoais, tais como as vestimentas, barba, cabelos etc. A gravura mostrava o paciente tal qual ele chegou à clínica. Era, de fato, um registro clínico. As figuras de willanistas tendiam a mostrar os pacientes despersonalizados, como bonecos inexpressivos. O que se observa no século XIX é a combinação dessas duas maneiras de representação: a que enfatizava o local da lesão (morfológica ou "compartimentalista") e a tradição clínica, que atentava para todo o paciente ${ }^{10}$ (Hennepe 2007, p. 48-49).

As formas de representação gráfica das doenças de pele ensejaram o aparecimento de uma "linguagem visual" própria. Ela faz parte do esforço para se apurar as formas de diagnóstico e de ensino médico. Aliada à clínica e à anatomia patológica, vai criar o espaço a ser ocupado por outra forma de linguagem visual do século XIX: a representação das doenças em cera, também conhecida por moulage. Tal linguagem vai ganhar expressão e se vincular à dermatologia, especialidade médica ascendente. 


\section{A moulage DeRmatológicA}

O surgimento da modelagem do corpo em cera estava no bojo da mudança nas formas de conhecimento anatômico, sobretudo a partir do Renascimento. Desde então, as práticas escolásticas foram paulatinamente abandonadas e adotou-se a observação direta do corpo dissecado (Wilson, 1987, p. 64). Como já dito, o objetivo da anatomia naquele momento era a verificação ou demonstração do texto, que ficava sob os olhos do professor, único autorizado a interpretá-lo.

A atividade de dissecar corpos era associada a algo ilícito e moralmente duvidoso, não obstante a aprovação pelas autoridades religiosas e seculares. Os cadáveres eram de criminosos executados, o que reforçava o estigma moral. Em nada contribuiu para melhorar essa imagem a prática de violação de sepulturas de cemitérios para o roubo de cadáveres a serem usados em dissecações (Wilson 1987, p. 68).

Desde o século XVI, houve uma mudança significativa na maneira como a dissecação era conduzida. $O$ foco passou a ser o anatomista e não mais o texto ou o "médico-professor". O ritual não visava simplesmente a comprovação do texto, tal como na tradição escolástica, mas a observação direta das estruturas internas. As figuras do demonstrator e do ostensor foram dispensadas e suas funções incorporadas pelo anatomista, que fazia a autópsia, ou seja, "via com os próprios olhos". Andreas Vesalius (1514-1564), anatomista belga autor da obra De humanis corporis fabrica (1543), realizava as dissecações dessa maneira.

O frontispício de Fabrica revela essa mudança nos rituais de dissecação. A cena mostra o próprio Vesalius conduzindo a abertura e manipulação do corpo. Ele não lê ou segura nenhum texto, indicando diretamente aos espectadores as estruturas internas do cadáver. Como indica Wilson (1987, p. 69), o ritual revela menos ostentação de hierarquia intelectual do que a performance do anatomista: mostra-se o corpo dissecado e também o corpo do próprio anatomista. O cadáver também participa ativamente da cena, aparecendo inclinado para frente, dividindo a atenção do espectador entre ele e o médico.

Essa transformação na forma de explorar o corpo foi acompanhada pelo desenvolvimento de técnicas de modelagem de peças em cera que representavam estruturas internas do corpo e se tornaram instrumentos preciosos para o ensino médico e para o conhecimento público da anatomia humana. Dados os embaraços para se conseguir cadáveres e conservá-los, a ceroplastia foi 
uma das soluções para representar e estudar os órgãos e as estruturas internas do corpo. Maneiras de preservação das peças anatômicas pelo maior tempo possível foram tentadas, mas o tempo de duração era limitado. A cera era moldada sem grande esforço, aceitava corantes e implantes orgânicos (pelos, cabelos, dentes etc.) que realçavam o realismo das peças (Ballestriero, 2009, p. 224). Para os cirurgiões, os modelos resolviam o problema de escassez de cadáveres usados em demonstrações anatômicas.

Para Poggesi (2006, p. 51), a primeira escola de ceroplastia teria sido fundada em Bolonha no século XVIII pelo pintor, escultor e arquiteto Ercolle Lelli (1702-1766). Desde o final do século anterior, a instrução anatômica tinha atingido tal importância que um teatro para essa atividade fora erigido no Pallazzo dell'Archiginnasio, onde funcionava a universidade bolonhesa. O intuito de Lelli, ao organizar a primeira coleção de peças, era servir ao ensino (Ballestriero, 2009, p. 225).

Outra destacada escola de modelagem em cera se formou em Florença, sob influência da escola de Bolonha. Em 1771 foi constituído o Museu de História Natural (também conhecido como "La Specola") pelo Grão-Duque da Toscana, Pedro Leopoldo de Lorena-Habsburgo. Sua intenção era reunir as coleções científicas espalhadas pelos palácios do Grão-Ducado (Poggesi, 2006, p. 46). A oficina ceroplástica foi criada pelo abade e diretor do museu Felice Fontana (1730-1805). Nos primórdios havia apenas um modelista, Giuseppe Ferrini. O próprio diretor se encarregou das dissecações até que outros funcionários pudessem ser contratados. Em 1773 foi admitido Clemente Susini (1754-1814), que ficou conhecido como o mais refinado modelista do museu.

A intenção de Fontana era utilizar as coleções não apenas para a instrução médica, mas também para a educação do público em geral, conforme indica Maerker (2006). Segundo a autora, o diretor acreditava que o corpo de conhecimentos da filosofia natural estaria acessível a qualquer um, desde que apresentado de maneira simples, sem rebuscamento. Os modelos em cera do corpo humano serviriam a esse propósito. Tal concepção baseava-se em teorias de aprendizagem sensualistas, que enfatizavam a percepção visual. Os modelos não deveriam representar uma simples descrição do corpo, mas também suas funções (Maerker, 2006, p. 302).

Vemos que as primeiras representações em cera se esforçavam para mostrar o corpo saudável e o funcionamento de órgãos e estruturas internas. Esses modelos buscavam representar de forma fidedigna a anatomia humana e traduzir as leis naturais, como pretendia Fontana. ${ }^{11}$ Contudo, o artista siciliano 
Gaetano Giulio Zumbo (1656-1701) já demonstrava a preocupação com os corpos mórbidos. Treinado na Escola de Anatomia de Bolonha, acredita-se que tenha trabalhado em Florença sob os auspícios da família Médici. Dada a sua formação religiosa (era abade), suas primeiras obras em cera refletiam suas crenças. A notoriedade veio pelos chamados "Teatros da Morte" (ou "Teatrini"), que expressavam o senso de precariedade da vida, a decadência do corpo e a morte. ${ }^{12}$

A modelagem em cera pode ser entendida como uma forma para aumentar a "objetividade" das representações sobre o corpo. Embora este tenha sido "dessacralizado" pelos estudos anatômicos, Le Breton nota que permanecem "a angústia e a culpa" que cercavam as dissecações, vistas como "violação da integridade humana" e "voyeurismo mórbido do interior do corpo". As figuras nos atlas anatômicos, notadamente o de Vesalius, ainda representavam os corpos em posturas que pagavam um tributo visível às representações anteriores do homem e do cosmos. ${ }^{13}$ Mesmo esfolados e dissecados, os corpos não se livram de sua humanidade. Essa tendência, que expressa o conflito presente no inconsciente dos artistas e anatomistas, permanecerá viva pelo menos até o século XVIII (Le Breton, 2011, p. 82-87).

Apesar desse conflito, a modelagem em cera também vai expressar o "homem da modernidade", separado de si, dos outros e do cosmos. Seguindo a intensificação do individualismo, entendido por Le Breton como a valorização da vida privada em detrimento da vida pública, o corpo se torna um fim em si mesmo. O "retalhamento" do corpo, a que se negava Vesalius, torna-se comum:

Colecionam-se os despojos ou fragmentos anatômicos por causa de sua particularidade, ou para melhor se impregnar, à imagem de Ambroise Paré [cirurgião francês], de um conhecimento direto e mais metódico do corpo, a fim de melhor nutrir a prática médica. Cindido do homem que ele encarna, e do qual não é mais do que o signo privado de valor, vestígio tornado indiferente de alguém que não é mais, torna-se lícito, a partir dessa representação, procurar e guardar, para sua edificação pessoal, os tumores, as pedras, os fetos, os membros malformados, ou conservar despojos anatomizados. (Le Breton, 2011, p. 90-91)

Se o anatomismo a partir da obra de Vesalius representou uma "mutação epistemológica” em relação às formas anteriores de compreensão e representação do corpo, como quer Le Breton, também é possível falar em fenômeno semelhante no que tange à mudança na cultura visual no século XIX, à qual 
alude Hennepe. Houve uma transformação ampla que permitiu entender e representar o corpo de forma parcelada nos atlas dermatológicos e nas peças de cera.

A representação de doenças em cera propriamente dita, a moulage, está associada às mesmas mudanças nas concepções de saúde e doença que influenciaram a produção dos atlas sobre as doenças de pele. A partir da metade do século XIX, o número de especialidades médicas aumentava, impelidas pelo avanço das técnicas cirúrgicas, do diagnóstico clínico mais refinado e da experimentação. Entre elas, estão a dermatologia e a venereologia, que se tornaram disciplinas reconhecidas no início do século XIX, ganhando autonomia em relação a outros campos de conhecimento médico (Haviland; Parish, 1970, p. 69). Contudo, a gênese dessas especialidades esteve associada ao desenvolvimento da anatomia patológica do final do século anterior (Schnalke, 1992).

Em seus primórdios, a anatomia patológica construiu a ideia de que as doenças estavam relacionadas a um órgão peculiar. Isso deu força à prática clínica, que se empenhava na observação dos doentes e na descrição dos sintomas. Os diagnósticos clínicos podiam ser confirmados pelas autópsias. Isso permitiu a identificação de novas doenças e a sua classificação. Os novos sistemas nosológicos se relacionavam com os órgãos e seus sistemas, servindo de suporte para a constituição de novas especialidades médicas (Schnalke, 1992, p. 134).

Contudo, é preciso fazer aqui uma breve digressão sobre o surgimento das especialidades médicas para compreender o papel conjunto desempenhado pela anatomia patológica e pela prática clínica no surgimento de novas áreas na medicina, sobretudo a dermatologia.

Na literatura sobre o tema, na qual George Rosen (1944) é autor pioneiro, as especialidades médicas não aparecem apenas como consequência do acúmulo de conhecimento, mas relacionam-se com a transformação das concepções sobre as doenças. As novas tecnologias que permitiram a construção de aparelhos como o oftalmoscópio e o laringoscópio também teriam sido decisivas para atrair o interesse dos médicos para os órgãos e os sistemas que eles integravam e em torno dos quais as especialidades poderiam se desenvolver (Weisz, 2003, p. 544).

George Weisz (2003, p. 539) propõe outra interpretação, que não descarta a hipótese que considera o avanço da patologia clínica e das tecnologias associadas como desencadeadoras do surgimento das especialidades médicas. O "localismo orgânico", contudo, não é suficiente para explicar o surgimento de ramos específicos do conhecimento e da atuação médica. Para o autor, a 
especialização pode ser vista como uma necessidade da moderna ciência médica, derivada do cumprimento de três pré-condições fundamentais: 1) a unificação da medicina com a cirurgia, permitindo que subcampos médicos ganhem significado; 2) o desejo de expandir o conhecimento médico, que favoreceu a especialização, pois esta teria permitido a observação empírica rigorosa de muitos casos em um só local (as enfermarias de hospitais); 3) a emergência da racionalidade burocrática no Estado-nação, fortemente ligada à necessidade do controle de populações, próximo ao sentido que Foucault (2006; 2008) lhe atribui.

Essas condições estavam presentes em Paris no século XIX, cidade na qual a ideia de especialidades médicas vai se desenvolver e se consolidar. Como já assinalado acima, após a Revolução Francesa a cirurgia foi incluída no currículo do ensino médico. Muitas especialidades não correspondiam a nenhum órgão ou sistema do corpo, tais como a medicina legal, a pediatria, a obstetrícia (o cuidado dado às mulheres grávidas) etc. Mesmo aqueles ramos "baseados organicamente" referiam-se a procedimentos cirúrgicos (Weisz, 2003, p. 545).

O fato de Paris estar na vanguarda da especialização pode ser explicado pela existência de uma comunidade de pesquisadores médicos preocupada com o rigor da observação empírica. A emergência da patologia orgânica e da especialização teriam respondido a essa preocupação, na visão de Weisz. Trata-se, sobretudo, de uma mudança de mentalidade, de uma nova atitude intelectual que incentivou a fragmentação do conhecimento em subáreas.

Aliada a essa nova maneira de pensar, há que se considerar a forma institucional da ciência francesa, que favoreceu o avanço científico e a especialização. As novas escolas superiores criadas em 1794 e 1800 estreitaram relações com outras instituições científicas. Era comum a partilha de estudantes, professores e pesquisadores entre a Faculdade de Medicina, a Sorbonne, o Collège de France, o Museu de História Natural e os hospitais. A divisão em disciplinas já presente nas ciências naturais serviu como modelo imediato para a medicina (Weisz, 2003, p. 549).

Ainda tratando da lógica administrativa adotada pelo Estado francês, Weisz menciona a divisão feita entre os hospitais, visível desde a criação do Hôpital Saint-Louis, em 1607, para isolar as vítimas da peste. Nos séculos XVIII e XIX essa tendência se acentuou. A lógica era muito mais administrativa, no sentido de distinguir e separar para oferecer melhor cuidado, do que orientada por critérios médicos. Contudo, o isolamento proporcionou aos médicos um vasto estoque de pacientes para ser estudado. O ensino e a 
pesquisa puderam ser aperfeiçoados pela observação sistemática e ao longo do tempo de várias categorias de doenças (Weisz, 2003, p. 553). As observações de um grande número de casos contribuíram para a validação do conhecimento das especialidades. Também diluiu a suposta oposição entre a prática clínica e a pesquisa médica, aproximando a clínica da anatomia patológica.

Contudo, a inclusão do ensino de especialidades no ensino médico encontrou forte oposição na Faculdade de Medicina, sobretudo quando elas incluíam a cirurgia. A especialização era vista dentro da instituição, ainda em 1859 , como uma forma perigosa de isolamento ou estreitamento intelectual. Ela poderia levar a uma fragmentação e à perda da "visão do todo". A resistência foi tamanha que o ensino de especialidades foi incluído à força no currículo. A partir de 1862, elas foram ensinadas em cursos complementares pelos agrégés, algo equivalente ao professor assistente ou não titular. É somente em 1879, por exemplo, que a cadeira de doenças da pele e doenças venéreas será incluída no currículo da Faculdade de Medicina de Paris (Weisz, 2003, p. 558-560). ${ }^{14}$

A interpretação sobre as especialidades sugerida por Weisz permite compreender por que Paris tornou-se um dos centros mais importantes de dermatologia no século XIX. Jean-Louis Alibert destacou-se, como vimos, por sua atuação no Hôpital Saint-Louis, que se especializou em doenças de pele. A moulage pôde prosperar graças à combinação da prática clínica e dos desenvolvimentos da anatomia patológica. Cumpre registrar, no entanto, que a conjugação de ambas, cujo resultado Foucault (2006, p. 149) chamou de "anatomoclínica", foi fruto de uma "litigiosa estruturação" na qual a clínica e a anatomia patológica entraram em conflito.

A prática da "educação da visão" ("teaching of the eye") no Hôpital Saint Louis já era adotada nas aulas de Alibert, que utilizava ilustrações, gravuras, aquarelas e pinturas a óleo para evidenciar com maior clareza para os seus alunos as doenças da pele. Tal prática facilitou a introdução da moldagem em cera no currículo de ensino da instituição, o que foi feito por Charles Lailler (1828-1898) na década de 1860. O colaborador mais destacado de Lailler foi Jules Pierre François Baretta (1834-1923), artista de origem belga, contratado pelo Saint Louis em 1870, que produziu aproximadamente 2 mil peças para o acervo do Hospital, além de suprir médicos particulares da França e de outros países. Adicionalmente, foi o principal modelista do Museu de Patologia do Saint Louis ${ }^{15}$ (Schnalke, 1992, p. 135).

Foi o Hôpital Saint Louis que sediou o Primeiro Congresso Internacional de Dermatologia e Sifiliologia, em 1889. Segundo Schnalke (1992), esse 
evento marcou o início do período de florescimento da arte da moldagem na Europa. A instituição francesa teve papel central na consolidação da disciplina e a influenciou até meados do século XX. O congresso deu publicidade às obras de Baretta, que puderam ser admiradas por médicos da Europa e de outras partes do mundo. De acordo com Schnalke (1992, p. 137), os médicos participantes, impressionados com a vivacidade ("vividness") das peças, voltaram para seus países com o interesse de formar coleções em seus próprios hospitais.

Como assinalam Haviland e Parish (1970, p. 69), ao final do século XIX todos os grandes centros de dermatologia (Paris, Londres, Viena) já possuíam importantes museus ceroplásticos. A coleção parisiense serviu de modelo para os demais hospitais dermatológicos europeus, e o congresso de dermatologia seguramente foi decisivo para a disseminação dessa técnica.

No mundo germânico, Viena foi o primeiro local onde a venéreo-dermatologia se institucionalizou como disciplina universitária. Von Hebra, com a colaboração de Anton Elfinger (1821-1864), introduziu a moldagem na dermatologia vienense, mas uma verdadeira "tradição" na área só seria possível com a colaboração entre o médico Moriz Kaposi e Carl Henning, já nos anos 1880. A influência do congresso parisiense, do qual participou Kaposi, foi marcante. Henning tinha formação médica e havia publicado um atlas de anatomia com imagens bidimensionais antes de se graduar. De acordo com Schnalke (1992), não se sabe como o jovem médico interessou-se pela modelagem em cera, mas supõe-se que ele tenha tido contato com os modelos de Elfinger por intermédio do oftalmologista vienense Johann Hofmayr.

Kaposi considerava que as peças em cera eram um valioso material para a prática clínica e educacional, pois poderia representar vividamente ("lifelike") uma parte do corpo afetado por uma doença. Inicialmente, a produção de peças era feita em anexo do consultório de Kaposi, mas com o sucesso, ele ganhou um ateliê no terreno do Hospital Geral de Viena. Henning participou com trabalhos no $10^{\circ}$ Congresso Internacional de Medicina Interna em Berlim (1890) e no Segundo Congresso Internacional de Dermatologia e Sifiliologia, organizado por Kaposi em Viena. Durante a Primeira Guerra Mundial, produziu próteses faciais para soldados que sofreram algum tipo de deformação no campo de batalha. Faleceu em 1917, mas o negócio de moldagem em cera foi continuado por seu filho, Theodor Henning.

Apesar da predominância dos Hennings, outros moldadores alcançaram alguma notoriedade em Viena: Alphons Raimond Poller (1879-1930) e seu aprendiz Maximilian Blaha (1905-?). Na década de 1930 foi organizado o 
Museu de Anatomia Patológica junto ao Hospital Geral, que reuniu trabalhos dos Henning, Poller e Blaha. Hoje, de acordo com Schnalke (1992, p. 140), a instituição tem uma coleção de 3 mil peças, a segunda maior da Europa.

\section{Moulage E OBJetividade CIENTÍficA}

A formação das especialidades médicas está relacionada não apenas com questões propriamente científicas ou cognitivas, mas também com diversos fatores como mudanças culturais, políticas e administrativas. É interessante notar que a definição de um novo campo de conhecimento médico não se dá exclusivamente por critérios científicos internos ao próprio campo e como resultado do desenvolvimento linear de uma racionalidade científica tida como universal.

Um aspecto importante da produção dos modelos em cera era a forma de sua validação, isto é, da sua aceitação como representação confiável e fiel do corpo humano e, na verdade, da própria natureza e de suas leis. No Museu La Specola, em Florença, os conflitos entre artistas e cientistas ficaram evidentes. Os artistas não tinham formação médica e o trabalho na oficina era supervisionado pelo diretor do museu, Felice Fontana. O diretor estabeleceu duas fontes principais de "autoridade" para a produção de peças em cera. A primeira era o conjunto de ilustrações retiradas dos trabalhos dos mais aclamados anatomistas da época, como Albinus, Haller, Mascagni, Vicq d'Azyr, Loder, Soemmering e Weitbrecht. A segunda era o uso de partes de corpos obtidas junto a hospitais locais ${ }^{16}$ (Maerker, 2006, p. 299).

Em linhas gerais, o processo de produção seguia estas etapas: um filósofo ou um cientista natural escolhia a ilustração de uma publicação renomada e que preferencialmente trouxesse os avanços mais recentes da anatomia; em seguida, o dissecador preparava partes de corpos reais de acordo com as ilustrações; por fim, os artesãos faziam o molde a partir das preparações (podia ser mais de uma da mesma parte do corpo) ou modelavam livremente, apenas observando as ilustrações e preparações. Feitos os moldes, eles eram preenchidos com cera derretida e, após a secagem, envernizados e pintados. Depois de prontos, eram representados em desenhos, também expostos ao público (Maerker, 2006, p. 299).

Havia um complicado processo para conferir credibilidade às peças, que, além dos procedimentos já citados, envolvia uma rede de colaboradores que davam sua aprovação a elas. Não bastava o esmero na produção, com a referência às obras clássicas de anatomia e a utilização de preparações 
derivadas de cadáveres. A aprovação externa também era necessária para garantir a precisão dos modelos. Essa rede envolvia naturalistas visitantes, médicos e anatomistas com os quais Fontana mantinha contato (Maerker, 2007, p. 262).

Esses eram os problemas de "autoridade cognitiva". Segundo Maerker (2007, p. 264), "autoridade cognitiva" significa "a capacidade socialmente aceita de falar a verdade sobre a natureza". A dependência financeira do artesão, o fato de ser assalariado, tornava "parcial" o seu trabalho. Somente o filósofo natural, que contava com meios próprios, seria verdadeiramente desinteressado e capaz de produzir "asserções verdadeiras". O que essa separação entre artesãos e naturalistas efetivamente revela é a oposição entre trabalho manual (artesãos) e trabalho intelectual (naturalistas), expressa nos termos de "autonomia" e "dependência".

Dentro da oficina do La Specola havia uma disputa entre os naturalistas, os anatomistas e os artesãos (Maerker, 2007). Para o diretor, os artesãos eram apenas "instrumentos": a autoridade não repousava nas competências artesanais. Como enfatiza Maerker (2007, p. 263), não havia a cooperação interdisciplinar entre naturalistas, anatomistas e artesãos idealizada por alguns historiadores e analistas da produção do La Specola. O que se via era a tentativa de cada um desses personagens garantir sua autonomia e o controle sobre o próprio trabalho.

Percebe-se que as questões de objetividade científica e validade das peças em cera estavam relacionadas com disputas extracientíficas ou não cognitivas. No caso das peças dermatológicas e sua relação com o surgimento do campo da especialidade, tais conflitos parecem ter sido menores ou menos relevantes. A moulage certamente se beneficiou do avanço da especialização e, mais do que isso, contribuiu para a formação e consolidação das especialidades às quais se associou.

Em meados do século XX a moulage perdeu importância, substituída por outras técnicas de representação e novas formas de documentação das doenças (Schnalke, 1993). A evolução da fotografia colorida e de modelos em plástico superou a ceroplastia, pois podiam ser reproduzidos indefinidamente e distribuídos com maior alcance. Os modelos em cera eram únicos e produzidos de forma artesanal, não respondendo mais às necessidades de um ensino médico cada vez mais massificado. Assumiram, assim, caráter sobretudo museológico e se tornaram referências fundamentais para historiadores da ciência e da medicina. 


\section{CONSIDERAÇÕES FINAIS}

Como vimos, as imagens, na descrição e representação das doenças cutâneas, ganharam impulso na virada do século XVIII para o XIX, graças aos desenhos e aquarelas de Robert Willan. O crescimento da importância da ceroplastia médica, por sua vez, veio no bojo da transformação da cultura visual, observável desde o Renascimento, mas ela está intimamente ligada à ênfase dada às representações pictóricas das doenças e ao que Hennepe (2007) chamou de "forte ligação entre classificação e visualização". Outra transformação na forma de representar as doenças, que será visível na ceroplastia, foi a crescente atenção dada às lesões, tendência vinda da anatomia patológica, e sua representação visual isolada ou localista, isto é, de apenas uma parte do corpo.

Podemos afirmar que a ceroplastia foi o "próximo passo" das mudanças na cultura visual e na maneira de conceber as doenças, mostrando uma maneira mais precisa e realista de representação das afecções da pele. Elas seriam uma forma de suprir as limitações dos desenhos, apontadas pelo próprio Willan. Elas contribuíram, assim, para consolidação da dermatologia como especialidade.

Como em outras disciplinas, as peças em cera também podem ter sido um tipo de "programa" para a dermatologia, elegendo as doenças socialmente importantes e trazendo-as para o âmbito dos estudos sobre a pele, como a sífilis. $^{17}$

Por fim, deve-se enfatizar que a ceroplastia só pôde aflorar graças a mudanças institucionais que, ao mesmo tempo, contribuíram para o surgimento das especialidades médicas, graças à junção, ainda que não sem conflitos, entre a prática clínica e o conhecimento advindo da anatomia patológica.

\section{REFERÊNCIAS}

BALLESTRIERO, Roberta. Anatomical models and wax Venuses: art masterpieces or scientific craft works? Journal of Anatomy, n. 216, p. 223-234, 2010.

BAKHTIN, Mikhail. A cultura popular na Idade Média e no Renascimento: o contexto de François Rabelais. São Paulo: Hucitec; Brasília: Ed. UnB, 2008.

BASTOS, Cristiana. Da anatomia à dermatologia: o corpo moldado em cera. In: BASTOS, Cristiana (org.). Clínica, arte e sociedade: a sífilis no Hospital do Desterro e na Saúde Pública. Lisboa: Imprensa de Ciências Sociais, 2011. 
BENCHIMOL, Jaime L. Adolpho Lutz e a dermatologia em perspectiva histórica. In: BENCHIMOL, Jaime L.; SÁ, Magali Romero (ed.). Dermatologia e micologia. Rio de Janeiro: Ed. Fiocruz, 2004. (Adolpho Lutz - Obra Completa, v. 1, Livro 3).

CARNEIRO, Glauco. História da Dermatologia no Brasil: dados sobre a especialidade e a sociedade científica. Rio de Janeiro: Sociedade Brasileira de Dermatologia, 2002.

CARRETA, Jorge Augusto. A ceroplastia e a medicina legal na Faculdade de Medicina da Universidade de São Paulo, 1934-1950. História, Ciências, Saúde - Manguinhos, Rio de Janeiro, v. 23, n. 3, p. 757-777, jul./set. 2016.

DI FOLCO, Philippe. Skin Art. Paris: Fitway, 2004.

FEND, Mechthild. Portraying Skin Disease: Robert Carswells's Dermatological Watercoulours. In: SIENA, Kevin; REINARZ, Jonathan (ed.). A Medical History of Skin: Scratching the Surface. London: Pickering and Chatto, 2013.

FOUCAULT, Michel. Nascimento da biopolítica. São Paulo: Martins Fontes, 2008.

FOUCAULT, Michel. O nascimento da clínica. Rio de Janeiro: Forense Universitária, 2006.

HAVILAND, Thomas N.; PARISH, Lawrence C. A Brief Account of Use of Wax Models in the Study of Medicine. Journal of History of Medicine and Allied Sciences, v. XXV, n. 1, p. 52-75, 1970.

HENNEPE, Mieneke Te. Depicting Skin: Microscopy and the Visual Articulation of Skin Interior 1820-1850. In: VAN DE VALL, Renée; ZWIJNENBERG, Robert. The Body Within: Art, Medicine and Visualization. Leiden: Brill, 2009. p. 51-65.

HENNEPE, Mieneke Te. Depicting Skin: Visual Culture in Nineteenth-Century Medicine. Wageningen: Ponsen \& Looijen, 2007.

LANE, John E. Robert Willan. Archives of Dermatology and Syphilology, v. 13, n. 6, p. 737-760, 1926.

LE BRETON, David. Antropologia do corpo e modernidade. Petrópolis, RJ: Vozes, 2011.

LEBRUN, François Se soigner autrefois: médecins, saints et sorciers aux XVIIe et XVIIIe siècles. Paris: Seuil, 1985.

LE GOFF, Jacques. Para uma outra Idade Média: tempo, trabalho e cultura no Ocidente. Petrópolis, RJ: Vozes, 2013.

MAERKER, Anna. The Anatomical Models of La Specola: Production, Uses and Reception. Journal of the History of Science, v. 21, n. 2, p. 295-321, 2006.

MAERKER, Anna. The Anatomical Models of la Specola: Production, Uses and Reception in Late Eighteenth-Century Florence. History of Science, v. 45, n. 3, p. 257286, 2007.

NOGUEIRA, Roberto P. Do físico ao médico moderno: a formação social da prática médica. São Paulo: Ed. Unesp, 2007.

POGGESI, Marta. The Wax Figure Collection in 'La Specola'. In: LAMERS-SCHUTZE, Petra; HAVERTZ, Yvonne (ed.). Encyclopaedia Anatomica: Museo La Specola Florence. Cologne: Taschen, 2006. 
PUSEY, William A. The History of Dermatology. New York: AMS, 1979.

ROSEN, George. The Specialization of Medicine: With Particular Reference to Ophthalmology. New York: Froben, 1944.

SCHNALKE, Thomas. A Brief History of Dermatologic Moulage in Europe - Part II: Breakthrough and Rise. International Journal of Dermatology, v. 31, n. 2, p. 134141, Febr. 1992.

SCHNALKE, Thomas. A Brief History of Dermatologic Moulage in Europe - Part III: Prosperity and Decline. International Journal of Dermatology, v. 32, n. 6, p. 453463, June 1993.

SENNETT, Richard. O declínio do homem público: as tiranias da intimidade. São Paulo: Companhia das Letras, 1988.

SIENA, Kevin; REINARZ, Jonathan (ed.). A Medical History of Skin: Scratching the Surface. London: Pickering and Chatto, 2013.

TILLES, Gérard ; WALLACH, Daniel. Les doctrines en dermatologie. In : TILLES, Gérard ; WALLACH, Daniel (ed.). La dermatologie en France. Toulouse: Éd. Privat, 2002. p. 63-76.

TODOROV, Tzvetan. A conquista da América: a questão do outro. São Paulo: Martins Fontes, 2010.

WEISZ, George. The Emergence of Medical Specialization in the Nineteenth Century. Bulletin of the History of Medicine, v. 77, p. 536-575, 2003.

WILSON, Luke. William Harvey's Prelectiones: The Performance of the Body in the Renaissance Theater of Anatomy. Representations, n. 17, p. 62-95, 1987.

WILSON, Philip K. Afterword: Reading the Skin, Discerning the Landscape: A Geo-Historical Perspective of Our Human Surface. In: SIENA, Kevin; REINARZ, Jonathan (ed.). A Medical History of Skin: Scratching the Surface. London: Pickering and Chatto, 2013. p. 209-220.

\section{NOTAS}

${ }^{1}$ Bakhtin (2008) argumenta que essa maneira de se perceber o corpo deveu-se a uma transformação cultural ocorrida entre o Renascimento e a ascensão da modernidade burguesa. Hennepe (2009) é outra autora que enfatiza essa transformação das representações sobre a pele a partir do estudo dos trabalhos dos microscopistas alemães entre 1820 e 1850.

${ }^{2}$ Em outras sociedades a pele também assume esse papel de portadora da identidade. Todorov (2010, p. 229-230) descreve os rituais de esfolamento entre os astecas. O sacrificado era ornado e vestido como um deus. Após sua morte era esfolado e outros índios vestiam sua pele, personificando aquele deus.

${ }^{3}$ Podemos citar com exemplos De humanis corpori fabrica (1543), de Andresa Vesalius; Anatomia del cuerpo (1560), de Juan Valverdede Amusco; Tabulae Anatomicae (1627), de 
Giulio Cassiero; Anatomia reformata (1651), de Thomas Bartholin; Anatomie generale des viscères en situation, de grandeur et couleur naturelle, avec l'angeologie, et la nevrologie de chaque partie du corps humain (1752), de Jacques Fabian Gautier d'Agoty.

${ }^{4}$ Sobre a unificação de "físicos" e cirurgiões no espaço hospitalar ver também: NOGUEIRA, 2007.

${ }^{5}$ Hennepe (2007, p. 23) cita os seguintes médicos-historiadores que concedem a primazia a Willan: LANE, 1926; HALDIN-DAVIS, 1931; PUSEY, 1979; CRISSEY; PARISH, 1981; TILLES; WALLACH, 2002. Glauco Carneiro é o representante brasileiro entre esses autores (CARNEIRO, 2002).

${ }^{6}$ Segundo Hennepe (2007, p. 24-25), Willan foi pioneiro no uso de imagens em livros que tratavam de doenças de pele. A classificação das doenças de pele por ele estabelecida, baseada no sistema nosológico de Josef Plenck (1735-1807), tornou-se conhecida graças ao trabalho de seu discípulo Thomas Bateman (1778-1821), que a divulgou e se encarregou das reedições de Description and Treatment of Cutaneous Diseases. Essa descrição das doenças de pele ficou conhecida pelo nome genérico de Willan-Bateman.

${ }^{7}$ Jean-Louis Alibert é considerado o fundador da dermatologia francesa. Atuando no Hôpital Saint-Louis desde 1799, chegou a médico-chefe em 1807. Publicou um influente tratado sobre as doenças de pele, Description des maladies de peau (1814), resultado da observação clínica naquele hospital entre 1806 e 1814 (HENNEPE, 2007, p. 37).

${ }^{8}$ Para Tilles \& Wallach (2002, p. 68), a história da dermatologia do século XIX e de quase todo século XX herdou o debate sobre a objetividade da classificação das doenças. Para os naturalistas, o método de Lineu subvertia a ideia de continuidade entre os seres, ordenados por uma corrente hierárquica. As espécies criadas por Lineu seriam arbitrárias e não refletiriam a "realidade objetiva". Assim, o problema da dermatologia parecia ser muito menos de aquisição de conhecimento do que de saber como organizá-lo.

${ }^{9}$ Entre os willanistas franceses estão Laurent Biett (1781-1840), Alpheé Cazenave (17951877), Camille Gilbert (1797-1866) e Pierre François Olive Rayer (1793-1867).

${ }^{10}$ Essa combinação já é visível nos anos 1830. A segunda edição do atlas de Pierre Rayer (1835) já exibia a mistura da abordagem da anatomia patológica com as observações advindas da prática clínica. O médico austríaco Ferdinand von Hebra (1806-1876) também é um exemplo da combinação dos dois estilos, visível em seu Atlas der Hautkrankheiten, publicado originalmente em 1856.

${ }^{11}$ Os modelos em cera eram feitos essencialmente para o estudo de anatomia humana e não de condições patológicas. Contudo, no Museu La Specola foram produzidos modelos obstétricos que mostravam partos normais e com complicações (HAVILAND; PARISH, 1970, p. 68).

${ }^{12}$ São exemplos dessa série "O triunfo do tempo", "A peste", "Sílfide" e "O enterro". Parte dessas figuras encontra-se hoje no Museu La Specola, em Florença. Para mais detalhes, ver: POGGESI, 2006. 
${ }^{13}$ As representações dos atlas de anatomia ainda traziam referências religiosas. Como exemplo, podemos citar o "anjo da anatomia" ou o "anjo esfolado", figura presente no atlas Anatomie generale des viscères en situation, de grandeur et couleur naturelle, avec l'angeologie, et la nevrologie de chaque partie du corps humain, de Jacques Gauthier d'Agoty (1717-1785), publicado em 1752 (LE BRETON, 2011, p. 84).

${ }^{14}$ Weisz (2003) nota que na mesma época (1860-1870) surgem novos jornais médicos de especialidades, dirigidos por médicos dos hospitais parisienses e da Faculdade de Medicina. Eram novos campos justamente prestes a serem aceitos no currículo médico.

${ }^{15}$ Schnalke (1992), avalia que a coleção de moulages do Hôpital Saint Louis ainda hoje é a maior do mundo, formada por mais de 4 mil peças.

${ }^{16}$ O Grão-Duque Pedro Leopoldo garantiu o fornecimento de cadáveres ao museu, oriundos dos hospitais locais. Por vezes, Fontana não utilizava os corpos e os mandava para o cemitério, causando a fúria dos médicos (MAERKER, 2007, p. 261-262).

${ }^{17}$ Ver o trabalho de Jorge Carreta, que apontou a importância da ceroplastia para a consolidação da Medicina Legal como especialidade dentro da Faculdade de Medicina da Universidade de São Paulo (CARRETA, 2016). Segundo o autor, as peças em cera, representando temas da Medicina Legal, espelharam um abrangente programa definido pelos médicos da faculdade. Também é importante o estudo de Cristiana Bastos, que mostra como as peças em cera são objetos e estratégias de conhecimento, representando as doenças, as categorias de diagnóstico, o programa de estudo e a própria especialidade médica (BASTOS, 2011).

Artigo recebido em 8 de agosto de 2019.

Aprovado em 12 de dezembro de 2019.

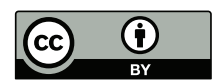

